\author{
И.В. Долгополова
}

\title{
СОЦИАЛЬНЫЕ СЕТИ В ЖИЗНИ \\ СТАРШЕКЛАССНИКОВ: СРАВНИТЕЛЬНЫЙ АНАЛИЗ ОЦЕНОК УЧАЩИХСЯ И РОДИТЕЛЕЙ
}

\begin{abstract}
Аннотация. Границы возраста пользователей социальных сетей становятся всё шире. Анализ роли социальных сетей как феномена интернета всё чаще проводится в негативном контексте. Между тем, влияние социальных сетей не так однозначно отрицательно. В связи с этим научный и прикладной интерес вызывает тема использования сочиальных сетей школьниками. Если личное общение детей является понятным для родителей и зачастую управляемым ими, то в отношении виртуального общения функция контроля взрослых минимальная. Поэтому актуальным является анализ оценок родителями и их детьми особенностей использования социальных сетей. Цель исследования - анализ и сопоставление роли социальных сетей в жизни старшеклассников с точки зрения школьников и их родителей. Также в работе решались задачи определения частоты и цели пребывания в социальных сетях у современных старшеклассников, выявления наиболее предпочитаемых социальных сетей и т.д. Предмет исследования - оценка роли социальных сетей в жизни старшеклассников учащимися и их родителями. Для решения задач работы из числа организационных методов применен сравнительный метод (группы школьников и их родителей по 47 человек в каждой), из числа психодиагностических - анкетирование и интервью. $B$ статье представлены результаты сопоставления оценок старшеклассников и их родителей о роли социальных сетей в жизни школьников: о количестве зарегистрированных аккаунтов, о целях применения социальных сетей, об их преимуществах и недостатках. В ходе исследования обнаружено, что оценки преимуществ и недостатков социальных сетей в целом одинаково понимаются старшеклассниками и их родителями. Выявлено, что различаются оценки родителей и их детей о частоте использования сочиальных сетей и их количестве. При этом родители серьёзно преувеличивают факты использования старшеклассниками социальных сетей в учебных целях, тогда как дети применяют их в первую очередь для свободного общения. Результаты работы могут быть интересны в научном плане для продолжения исследования в направлении разработки технологии общения детей в социальных сетях. Также они могут быть применены в прикладном плане - в части психолого-педагогической подготовки учителей, просвещения родителей, а также при проведении психологических консультаций.
\end{abstract}

Ключевые слова: сочиальные сети, виртуальное общение, интернет, зависимость, многозадачность, аккаунт, выбор сети, зависимый пользователь, независимый пользователь, незаинтересованный пользователь.

Abstract. The age of social network users is constantly extending. Researchers often view the role of social networks as a negative Internet phenomenon. However, the impact of social networks is not so definitely negative. In this regard, the authors of the present article have decided to analyze the topic of school students using social networks both in the theoretical and practical sense. Meanwhile interpersonal relations of children are often well understood and managed by their parents, virtual communication is not so easy to be managed. For this purpose, the authors have decided to analyze evaluations of social networks provided by children and their parents. The purpose of the research is to analyze and compare roles of social networks in the life of high school students from the view of school students themselves as well as their parents. The research objectives also include to define the frequency and purposes of high school students using social networks, to determine the most popular social networks, etc. The subject of the research is the evaluation of the role of social networks in the life of high school students given by students and their parents. To achieve the research objectives, the author has used the comparative research method to analyze groups of high school students and their parents, 47 people per each, as well as such psychodiagnostic methods as questionnaries and interviews. In her article Dolgopolova presents the results of comparing evaluations provided by school students and their parents regarding the role of social networks in their life including the number of registered accounts, reasons of why school students use social networks, advantages and disadvantages of social networks. The results 


\section{Психология и психотехника 10(97) • 2016}

of the research demonstrate that both children and their parents have a similar understanding of what minuses and pluses of social networks are. However, parents and their children have a different evaluation of how frequent they use social networks as well as the number of social networks. Noteworthy that parents tend to exaggerate the fact that their children may use social networks for academic reasons why children use social networks mostly for communication. The results of the research can be used in further researches of developing social technologies and social communication of children in social networks. The results can be also used in the practical sense, particularly, for psychological and pedagogical training of teachers, parents and during psychological sessions.

Key words: social network, virtual communication, Internet, addiction, multitasking, account, choice of network, dependent user, independent user, uninterested user.

$\mathrm{H}$ а сегодняшний момент высказывание «XXI век - век информационных технологий», наиболее точно характеризует пространство, в котором растёт, развивается и реализуется современный человек. Всё больше людей в профессиональной и учебной деятельности, в личной жизни и в близких отношениях вовлечены в виртуальное пространство. Налицо тенденция, при которой термин «Интернет» стал содержать в себе не только технический, но и социальный смысл. Глобальная сеть Интернет сегодня представляет собой место для удовлетворения потребностей, решения политических, экономических, социальных и других проблем, способ зарабатывать деньги, а также место для проведения досуга $[1 ; 4 ; 6]$.

Не так давно в Интернете появилось такое явление, как социальные сети, и буквально за пару лет они стали настолько популярны, что теперь практически у каждого интернет-пользователя есть своя страничка в той или иной социальной сети. С развитием интернет-технологий общение приняло совершенно иные формы, так что сегодня нам фактически не нужно встречаться лицом к лицу - достаточно зайти в Интернет, и перед нами открывается целый мир [5;9].

Анализ актуальных исследований, мониторинг социальных сетей позволяют выделить несколько трендов в их развитии.

Тренд 1 - сегодня социальные сети приобрели вполне конкретные очертания с точки зрения их целевого назначения:

- $\quad$ это некий сайт, который объединяет людей по конкретным признакам - профессиональным, социальным и прочим;

- $\quad$ это виртуальное пространство, где посетители могут выяснять интересующие вопросы (при помощи форума или чата, например);

- $\quad$ это страничка в сети, где можно составить портрет своей личности и найти нужные контакты;

- $\quad$ это место общения для обсуждения интересующих тем.

Тренд 2 - увеличение количества времени, проводимого в социальных сетях, формирует но- вый вид общения - «виртуальное». Его возможности постоянно расширяются: в виртуальном мире можно не только общаться, но и узнавать новости, развлекаться, саморазвиваться. Намечается формирование феномена альтернативного общения людей - без непосредственного контакта.

Тренд 3 - разнообразие социальных сетей заставляет задуматься о новом этапе во взаимоотношениях людей, формирование которых будет зависеть от конкуренции между сетями.

Некогда один из первопроходцев «Facebook» наделал много шума, и на данный момент численность зарегистрированных аккаунтов достигла одного миллиарда. Российские сети в лице «Вконтакте» и «Одноклассники» стараются конкурировать, но получается это лишь в пределах СНГ. Многие специалисты признают тот факт, что Twitter несправедливо отодвинут на второй план. «В контакте» удивляет ростом пользователей из числа молодёжи. «Instagram» захватывает всё большее количество публичных людей, благодаря возможности удобного размещения фотографий и текущих событий. Популярность ICQ и Mail стоит на месте - это видно по годовым отчётам двух компаний. Возможно, что для быстрого обмена сообщениями кому-то достаточно и привычного Агента, а не страницы ВК, но всё же разработчики социальных сетей не устают удивлять пытливых пользователей новыми приложениями. Конкуренция между сетями возрастает и грозит вылиться в настоящие «социальные» войны с проигравшими и победителем, которому достанется большее количество пользователей Интернета [9].

Тренд 4 - омоложение возраста начала использования социальных сетей. Если раньше считалось, что основной группой пользователей являются подростки и молодёжь, то сейчас регистрироваться в социальных сетях начинают пользователи в среднем с 10 лет, а иногда и раньше [7; $10 ; 11 ; 12 ; 13]$.

Результаты современных исследований показывают, что влияние социальных сетей на жизнь современных школьников проявляется во многих аспектах: 


\section{Психология и педагогика}

1. Зависимость: от $5 \%$ до $10 \%$ пользователей практически не способны отмерять время, проведённое онлайн. Поскольку социальные медиа приносят «вознаграждение», не требуя для этого особых усилий, мозг перенастраивает сам себя, вызывая страстное желание получать как можно больше таких «вознаграждений» - лайков, классов и пр.

2. Многозадачность: общение онлайн, связанное с необходимостью выполнять разнообразные функции, снижает способность мозга отфильтровать помехи, и даже может усложнить процесс запоминания.

3. Синдром фантомной вибрации - это относительно новый психологический феномен, когда пользователю начинает казаться, что телефон вибрирует в ответ на пришедшее сообщение, хотя он молчит. В одном исследовании 99\% испытуемых признались, что испытывают такое, по крайней мере, однажды каждые две недели.

4. Выработка дофамина: общение в социальных сетях усиливает выработку этого гормона, вызывающего чувство удовольствия и удовлетворения. Естественным образом он вырабатывается, например, во время вкусного обеда. Учёные обнаружили, что центры вознаграждения в мозге человека гораздо более активны, когда он говорит о себе самом, а не слушает других. Только 30-40\% беседы лицом к лицу с партнёром получается посвятить самому себе и своим переживаниям, а вот при общении в социальных сетях - все 80\%. Когда мы используем виртуальное общение, стимуляцию получает та же часть мозга, что связана с мотивацией и любовью. Т.е., организм физиологически награждает нас за то, что мы так много говорим о себе онлайн [8; 14; 15].

Перечисленные факторы свидетельствуют, что исследования стали сосредотачиваться в направлении изучения виртуальной зависимости, интернет-аддикции [2]. Анализ роли социальных сетей как феномена интернета всё чаще проводится в негативном контексте.

Между тем влияние социальных сетей не так однозначно отрицательно. С одной стороны, Интернет изменил наше вербальное общение и при недостаточной готовности к общению в виртуальном мире рискует сформировать поведенческие деформации во взаимодействии. Но с другой стороны, он облегчил взаимодействие людей, которые разделены пространством и временем.

Оценка социальных сетей и их роли в жизни человека наиболее актуальна именно в отношении детей старшего подросткового возраста. Старшеклассники больше времени в сравнении с младшей и средней школой проводят вне контроля родителей, они более самостоятельны и продвинуты в использовании информационно-коммуникативных технологий. Поэтому к старшим классам среди школьников возрастает число тех, которые, не освоив в полной мере личное общение, погрузились в формат виртуального взаимодействия. Выше обозначенные четыре тренда в становлении социальных сетей наиболее активно проявляются именно в этой возрастной группе.

Некоторые исследования в области изучения социальных сетей уже представлены в работах учёных. Так, М.М. Шубович и Ю.А. Якутовой (2012 г.) рассмотрены основные формы виртуального взаимодействия старшеклассников в сети Интернет, критерии и уровни социальной активности в сфере Интернет-технологий, а также описаны необходимые педагогические условия, определяющие успешность процесса формирования Интернет-культуры старшего школьника [14]. В исследовании О.А. Гуркиной и Д.В. Мальцевой проведён анализ причин популярности виртуальных сетей среди подростков. Наряду с освещением основных теоретических подходов к проблеме, представлены результаты опроса московских старшеклассников, которые показали особое значение рекреационных возможностей социальных сетей для подростков [3].

В имеющихся на сегодня работах прослеживается мысль - Интернет активно и динамично войдёт в нашу жизнь, поэтому следует признать неизбежность данного явления в повседневной жизни. Использование социальных сетей как инструмента развития старшеклассников возможно при условии взаимного соответствия взглядов детей и воспитывающих взрослых на этот феномен.

Для изучения общности взглядов на роль социальных сетей в жизни человека у школьников и их родителей было проведено данное исследование. Цель работы: анализ и сопоставление роли социальных сетей в жизни старшеклассников с точки зрения школьников и их родителей. Также в ходе исследования решались задачи:

- выявить частоту и цели пребывания в социальных сетях у современных старшеклассников;

- изучить наиболее предпочитаемые социальные сети;

- сопоставить оценки старшеклассников и их родителей в определении роли социальных сетей.

В качестве гипотезы была положена мысль о том, что старшеклассники и их родители поразному оценивают роль социальных сетей в жиз- 


\section{Психология и психотехника 10(97) • 2016}

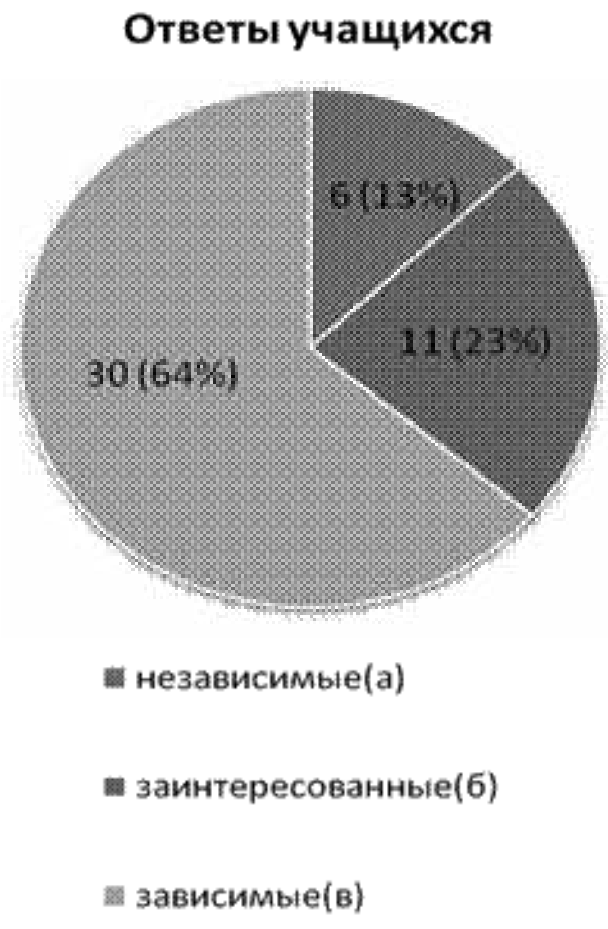

Рис. 1. Распределение учащихся на группы в зависимости от времени, проводимого в социальных сетях

ни школьников. Во-первых, предположено, что дети проводят в социальных сетях почти всё своё свободное время, являясь пользователями нескольких социальных сетей, при этом родители дают неверные оценки времяпрепровождения их детей в социальных сетях. Во-вторых, предположено, что старшеклассники выделяют больше положительных сторон влияния социальных сетей на свою жизнь в отличие от их родителей, которые отмечают больше отрицательных моментов.

Суть исследовательской работы сводилась к изучению оценок социальных сетей в жизни старшеклассников с их точки зрения, а также с точки зрения их родителей. Далее осуществлялось сопоставление их оценок. В исследовательской работе приняли участие 47 школьников 10-х классов и их родители (всего в исследовании участвовало 94 человека).

Значительное место в исследовательской практике специалистов, разрабатывающих проблематику зависимости от Интернета, занимают качественные методы. Большая часть исследований методически построена как интервью, массовые сетевые опросы и групповые обсуждения с участием испытуемых [2]. В рамках нашего исследования диагностика также проводилась традиционными качественными методами интервью и анкетирования.
В рамках первого этапа исследования школьники отвечали на вопросы о том, сколько времени они проводят в социальных сетях, в каких социальных сетях они состоят, для каких целей ученики используют социальные сети, каковы достоинства и недостатки социальных сетей.

По результатам ответов школьников на первый вопрос анкеты, они были разделены на три группы пользователей социальных сетей по фактору времени, проводимого в социальных сетях (рис. 1). Этот фактор показывает, сколько свободного времени школьники тратят на виртуальное общение. Свободное время определялось как «остаток времени в течение дня» от занятого учебной деятельностью (включая обучение в школе и выполнение домашних заданий) и режимными моментами (например, время сна). Условно, названные «зависимые» - это старшеклассники, которые ежедневно проводят в социальных сетях больше 3 часов в день (более $50 \%$ свободного времени), «заинтересованные» пользователи тратят на это от 1 до 3 часов в день, а «независимые» находятся в социальных сетях менее 1 часа в день (менее 15\% свободного времени).

Как видно, наибольшее количество учащихся (64\%) - это зависимые пользователи от телефонов, компьютеров и прочих гаджетов. Примером может служить ответ одного из участников исследования - «я и 5 минут без телефона не могу». Вторая по численности группа (23\%) - это заинтересованные пользователи, которые применяют социальные сети только по существу и в ситуациях, когда им это действительно нужно. Наименее представлены среди старшеклассников независимые пользователи социальных сетей, их всего $13 \%$. Согласно интервью, в их жизни преобладает реальное общение.

На втором этапе исследования опросник с аналогичным содержанием был выдан родителям учащихся, чтобы они ответили на вопросы о роли социальных сетей в жизни их детей. Далее нами было проведено сравнение ответов детей и родителей (табл. 1).

Родители отмечали тот ответ, который соответствовал времени ежедневного пребывания в социальных сетях их детей. По результатам исследования, которые представлены в таблице 1, мы видим, что и школьники, и родители в равной степени признают большинство зависимых детей, проводящих в сети более 3 часов ежедневно. Но следует отметить существенное различие в распределении детей в группе заинтересованных: 42,5\% родителей считают, что их дети проводят в сетях от 1 до 3 часов в день, а по факту лишь 23,5\% детей 
Сравнение ответов учащихся и родителей о времени, проводимом в социальных сетях

Таблица 1.

\begin{tabular}{|c|c|c|c|}
\hline Группы пользователей & Независимые & Заинтересованные & Зависимые \\
\hline Время, проводимое в социальных сетях & менее 1часа в день & от 1 до 3 часов в день & более 3 часов ежедневно \\
\hline Оценки учеников & $6(12,7 \%)$ & $11(23,5 \%)$ & $\mathbf{3 0}(\mathbf{6 3 , 8})$ \\
\hline Оценки родителей & $5(10,7 \%)$ & $20(42,5 \%)$ & $\mathbf{2 2 ( 4 6 , 8 \% )}$ \\
\hline
\end{tabular}

Таблица 2.

Сравнение ответов детей и их родителей в области приоритета социальных сетей и их рейтинга

\begin{tabular}{|c|c|c|c|c|c|c|c|c|}
\hline & & ВКонтакте & Одноклассники & Facebook & Twitter & Мой мир & Instagram & Другое \\
\hline \multirow{2}{*}{ 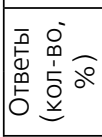 } & ШКОльникИ & $\begin{array}{c}46 \\
(97,8 \%)\end{array}$ & $\begin{array}{c}7 \\
(14,9 \%) \\
\end{array}$ & $\begin{array}{c}14 \\
(29,8 \%) \\
\end{array}$ & $21(44,7 \%)$ & $29(61,7 \%)$ & $\begin{array}{c}27 \\
(57,4 \%) \\
\end{array}$ & $10(21,3 \%)$ \\
\hline & родители & $\begin{array}{c}45 \\
(95,7 \%)\end{array}$ & $\begin{array}{c}8 \\
(17,1 \%)\end{array}$ & $\begin{array}{c}9 \\
(19,1 \%)\end{array}$ & $8(17,1 \%)$ & $16(34,0 \%)$ & $21(44,7 \%)$ & $2(4,2 \%)$ \\
\hline \multirow{2}{*}{ 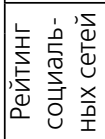 } & ШКОЛЬНИКИ & 1 & 7 & 5 & 4 & 2 & 3 & 6 \\
\hline & родители & 1 & 5 & 4 & 5 & 3 & 2 & 6 \\
\hline
\end{tabular}

Сравнение оценок родителей и учащихся о количестве социальных сетей, в которых состоит старшеклассник

\begin{tabular}{|c|c|c|c|c|}
\hline \multirow{2}{*}{$\begin{array}{c}\text { Количество } \\
\text { социальных сетей }\end{array}$} & \multicolumn{2}{|c|}{ Мнение учащихся } & \multicolumn{2}{|c|}{ Мнение родителей } \\
\hline & Число выборов & \% выборов & Число выборов & \% выборов \\
\hline 1 & 7 & $14,9 \%$ & 19 & $40,5 \%$ \\
\hline 2 & 10 & $21,2 \%$ & 12 & $25,6 \%$ \\
\hline 3 & 11 & $23,5 \%$ & 7 & $14,9 \%$ \\
\hline 4 & 8 & $17,1 \%$ & 6 & $12,7 \%$ \\
\hline 5 & 5 & $10,7 \%$ & 3 & $6,4 \%$ \\
\hline 6 & 3 & $6,4 \%$ & - & - \\
\hline 7 & 3 & $6,4 \%$ & - & - \\
\hline
\end{tabular}

относят себя к заинтересованным. Сами дети утверждают, что это время составляет более 3 часов.

Далее проанализируем ответы детей о распределении социальных сетей, которыми они пользуются (рис. 2).

Диаграмма демонстрирует самые популярные социальные сети среди старшеклассников. Тройка лидеров - это ВКонтакте (им пользуются 98\% респондентов), Мой мир (62\%) и Instagram (57\%).

Сопоставление ответов школьников и их родителей показало, что они в целом совпадают (табл. 2).

Тройка востребованных социальных сетей у старшеклассников и их родителей совпала - это ВКонтакте, Instagram и Мой мир. Даже если родители являются пользователями сети «Одноклассники», они вполне понимают, что дети ориентированы на другие ресурсы.

В ходе опроса выяснилось, что некоторые школьники используют несколько социальных сетей (табл. 3).

По данным табл. 3 можно отметить, что родители не ориентируются в том, в скольких социальных сетях состоит их ребёнок. Они не подозревают, что ребёнок может быть зарегистрирован в 6 или даже 7 социальных сетях. Можно так же отметить,
Приоритет социальных сетей среди старшеклассников

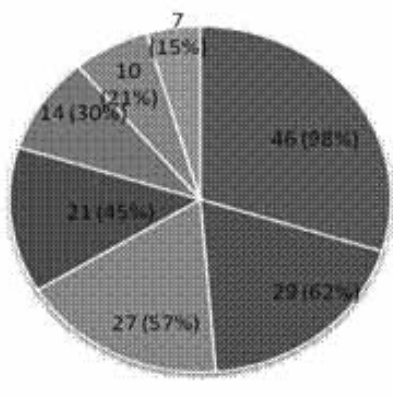

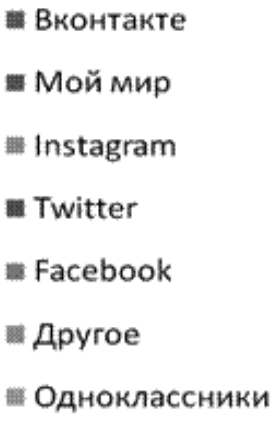

Рис. 2. Приоритет в выборе используемых социальных сетей среди старшеклассников

что большинство учащихся состоят в 2 или 3 социальных сетях, что вместе составляет 44,7\%. В то время как 40,5\% родителей считают, что их ребёнок является пользователем только одной социальной сети.

Интересным представляется анализ целей использования социальных сетей (рис. 3).

Цели использования старшеклассниками социальных сетей вполне прогнозируемы: обще- 


\section{Психология и психотехника 10(97) • 2016}

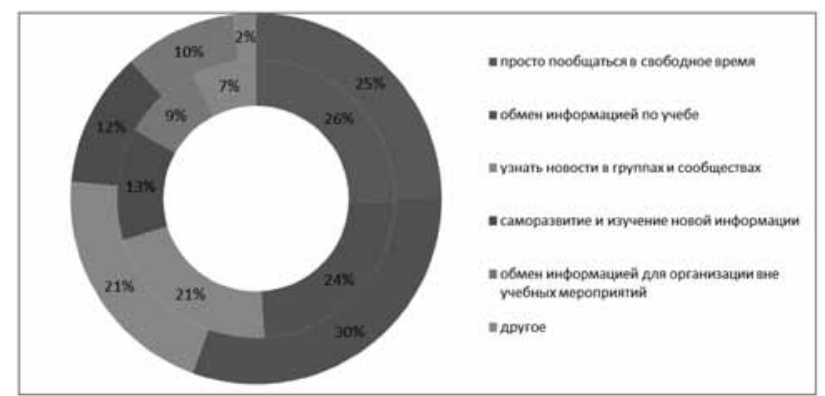

Рис. 3. Цели использования социальных сетей, по мнению детей и их родителей

* По внешнему кругу диаграммы представлены оценки родителей, по внутреннему кругу - оценки детей.

ние, обмен информацией и получение новостей. Родители также называют эти цели в числе трёх приоритетных, но они несколько преувеличивают использование детьми социальных сетей с целью обмена информацией по учёбе. Для школьников в приоритете целей использования социальных сетей - «просто пообщаться в свободное время».

И школьники, и их родители признают существенную роль социальных сетей в современной жизни, они также выделяют их преимущества (табл. 4).

Таблица 4.

Сравнение оценок детей и их родителей о преимуществах социальных сетей

\begin{tabular}{|c|c|c|}
\hline \multirow[b]{2}{*}{$\begin{array}{c}\text { Перечень } \\
\text { преимуществ }\end{array}$} & \multicolumn{2}{|c|}{ Количество ответов } \\
\hline & $\begin{array}{c}\text { Учащиеся, кол-во } \\
\text { (\%), рейтинг }\end{array}$ & $\begin{array}{c}\text { Родители, кол-во } \\
(\%), \text { рейтинг }\end{array}$ \\
\hline $\begin{array}{l}\text { Общение } \\
\text { на расстоянии }\end{array}$ & $20(42,5 \%), 1$ & $8(17,1 \%), 3$ \\
\hline Доступность & $12(25,6 \%), 3$ & $10(21,2 \%), 2$ \\
\hline Скорость & $10(21,2 \%), 4$ & $8(17,1 \%), 3$ \\
\hline Новая информация & $18(38,2 \%), 2$ & $24(51,0 \%), 1$ \\
\hline Музыка & $7(14,9 \%), 5$ & \\
\hline Знакомств & $6(12,7 \%), 6$ & $6(12,7 \%), 4$ \\
\hline Саморазвитие & $4(8,5 \%), 7$ & $2(4,3 \%), 5$ \\
\hline Расслабление & $2(4,3 \%), 9$ & - \\
\hline \begin{tabular}{|l|} 
Пишешь, \\
что угодно
\end{tabular} & $3(6,4 \%), 8$ & - \\
\hline
\end{tabular}

Старшеклассники выделяют достоинств относительно больше, нежели их родители. Для детей важны такие факторы как «общение на расстоянии» $(42,5 \%)$, «получение новой информации» $(38,2 \%)$ и «доступность» $(25,6 \%)$. Родители главным преимуществом считают «получение новой информации» (51\%). В этом и заключается принципиальное различие в видении преимуществ социальных сетей детьми и их родителями. Современным старшеклассникам нужно, чтобы всё было доступно, быстро и понятно, но они очень часто забывают про качество. В то время как родителям важны знания и новая информация, которые помогают развиваться личности ребёнка.
Интересным было сравнение мнений групп респондентов о недостатках социальных сетей (табл. 6).

Таблица 6.

Сравнение мнений детей и их родителей о недостатках социальных сетей

\begin{tabular}{|l|c|c|}
\hline Перечень недостатков & \multicolumn{2}{|c|}{ Количество ответов } \\
\cline { 2 - 3 } & $\begin{array}{c}\text { Учащиеся, } \\
\text { кол-во (\%), } \\
\text { рейтинг }\end{array}$ & $\begin{array}{c}\text { Родители, } \\
\text { кол-во (\%), } \\
\text { рейтинг }\end{array}$ \\
\hline Неживое общение & $\mathbf{1 1 ( 2 3 , 5 \% ) , \mathbf { 3 }}$ & $\mathbf{1 5 ( 3 1 , 9 \% ) , \mathbf { 2 }}$ \\
\hline Формируют зависимость & $\mathbf{1 7 ( 3 6 , 2 \% ) , \mathbf { 2 }}$ & $\mathbf{8 ( 1 7 , 1 \% ) , \mathbf { 3 }}$ \\
\hline Падает зрение & $4(8,5 \%), 6$ & $\mathbf{8 ( 1 7 , 1 \% ) , \mathbf { 3 }}$ \\
\hline Занимают много времени & $\mathbf{1 8 ( 3 8 , 2 \% ) , \mathbf { 1 }}$ & $\mathbf{1 8 ( 3 8 , 2 \% ) , \mathbf { 1 }}$ \\
\hline Способ обмана & $6(12,7 \%), 4$ & $3(6,4 \%), 4$ \\
\hline Деградация личности & $5(10,7 \%), 5$ & - \\
\hline Ложная информация & $5(10,7 \%), 5$ & - \\
\hline Отвлекают от учебы & - & $\mathbf{8 ( 1 7 , 1 \% ) , 3}$ \\
\hline
\end{tabular}

Недостатков, так же как и преимуществ, дети выделили больше, чем их родители. Старшеклассники и их родители солидарны в том, что самый главный недостаток социальных сетей - это затраты времени $(38,2 \%$ и у детей, и у родителей). T.e. сами старшеклассники понимают, насколько плотно социальные сети вошли в их жизнь. Представителей обоих поколений волнует отсутствие живого общения и формирование зависимости от социальных сетей. Дети в социальных сетях видят больше опасностей, чем родители. И это следует признать позитивным фактором, так как осознание негативного влияния социальных сетей позволит школьникам критически относиться к их возможностям.

Проведённое исследование позволяет сделать ряд выводов:

1. время, которое проводят старшеклассники в социальных сетях, их родители оценивают недостоверно, существенно занижая его;

2. родители не ориентируются в количестве социальных сетей, пользователями которых являются их дети. Разность оценок существенная - в 2-3 раза;

3. школьники и их родители одинаково оценивают популярные среди старшеклассников социальные сети, относя к ним ВКонтакте, Instagram и Мой мир;

4. старшеклассники и их родители позиционируют одни и те же цели использования социальных сетей, но последние несколько завышают роль виртуального общения для учёбы;

5. в отношении преимуществ социальных сетей мнения представителей двух поколений сходятся - это общение на расстоянии, получение новой информации и доступность. В качестве главного недостатка и те, и другие признают большие потери времени; 


\section{Психология и педагогика}

6. предназначение социальных сетей для детей их родители оценивают как помощь в учёбе, а старшеклассники - как инструмент для общения.

Проведённая работа позволяет наметить дальнейшие направления исследований. Очевидно, виртуальное общение вступило в фазу вполне реальной конкуренции с личным взаимодействием. И здесь требуется исследование динамики возрастных факторов привыкания к общению в социальных сетях, продуктивных технологий взаимодействия, поиска способов приучения детей к балансу личного и виртуального общения, где приоритетной является роль родителей.

\section{Список литературы:}

1. Баткаева Е.Р. Феномен виртуализации: социологический аспект // Известия ПГПУ им. В.Г. Белинского. 2012. № 28. С. 35-37.

2. Войскунский А.Е. Актуальные проблемы психологии зависимости от интернета // Психологический журнал. 2001. T. 25. № 1. С. 90-100.

3. Гуркина О.А., Мальцева Д.В. Мотивы использования виртуальных социальных сетей подростками // Социологические исследования. 2015. № 5 (373). С. 123-130.

4. Ефимова Г.З., Зюбан Е.В. Влияние социальных сетей на личность // Мир науки. 2016. № 5. С. 20.

5. Кирка А.В. К вопросу о структуре социально-сетевых коммуникаций // Политика и общество. 2015. № 7. С. 863-872.

6. Коновалова Л.В. Социальные сети как новый фактор социализации российских школьников // Управление мегаполисом. 2015. Т. 1. № 3. С. 60-65.

7. Пронина Н.А. Роль социальных сетей в системе воспитания школьников // Новые технологии. 2011. № 1. С. 174-189.

8. Саглай И.В. Образовательные возможности социальной сети «Вконтакте» при обучении школьников старшей ступени русскому языку // Проблемы педагогики. 2015. № 2 (3). С. 27-30.

9. Селин П. Многообразие социальных сетей. [Электронный ресурс] URL: http://posledneeslovo.ru/raznoobraziesocialnyx-setej.

10. Серый А.В., Паршинцева А.С. К проблеме формирования зависимости от социальных сетей у школьников подросткового возраста // Проблемы педагогики. 2016. № 9 (20). С. 12-15.

11. Скачков М.А., Утёмов В.В. Влияние социальных сетей на формирование личности современного подростка // Концепт: научно-метод. журнал. 2013. № 8. С. 69-73.

12. Челышева И.В. Социальные сети в жизни современных школьников // Медиаобразование. 2014. № 2. С. 121-126.

13. Шахмартова О.Н., Недошивина И.В. Исследование мотивов использования социальных сетей младшими школьниками // Известия Пензенского государственного педагогического университета им. В.Г. Белинского. 2012. Вып. № 28. С. $1348-1353$.

14. Шубович М.М., Якутова Ю.А. Социальная активность старшеклассников в сфере современных информационных технологий как результат формирования интернет-культуры // Вестник Орловского государственного университета. Серия «Новые гуманитарные исследования». 2012. № 7. С. 238-241.

15. Юрьева Е.А. Влияние социальных сетей на социализацию и систему ценностных ориентаций старших школьников // Вестник Красноярского государственного педагогического университета им. В.П. Астафьева. 2012. № 4 (22). С. $218-221$.

\section{References (transliterated):}

1. Batkaeva E.R. Fenomen virtualizatsii: sotsiologicheskii aspekt // Izvestiya PGPU im. V.G. Belinskogo. 2012. № 28. S. 35-37.

2. Voiskunskii A.E. Aktual'nye problemy psikhologii zavisimosti ot interneta // Psikhologicheskii zhurnal. 2001. T. 25. № 1. S. 90-100.

3. Gurkina O.A., Mal'tseva D.V. Motivy ispol'zovaniya virtual'nykh sotsial'nykh setei podrostkami // Sotsiologicheskie issledovaniya. 2015. № 5 (373). S. 123-130.

4. Efimova G.Z., Zyuban E.V. Vliyanie sotsial’nykh setei na lichnost’ // Mir nauki. 2016. № 5. S. 20.

5. Kirka A.V. K voprosu o strukture sotsial'no-setevykh kommunikatsii // Politika i obshchestvo. 2015. № 7. S. 863-872.

6. Konovalova L.V. Sotsial'nye seti kak novyi faktor sotsializatsii rossiiskikh shkol'nikov // Upravlenie megapolisom. 2015 . T. 1. № 3. S. 60-65.

7. Pronina N.A. Rol' sotsial'nykh setei v sisteme vospitaniya shkol'nikov // Novye tekhnologii. 2011. № 1. S. 174-189.

8. Saglai I.V. Obrazovatel'nye vozmozhnosti sotsial'noi seti «Vkontakte» pri obuchenii shkol'nikov starshei stupeni russkomu yazyku // Problemy pedagogiki. 2015 № 2 (3). S. 27-30.

9. Selin P. Mnogoobrazie sotsial'nykh setei. [Elektronnyi resurs] URL: http://posledneeslovo.ru/raznoobrazie-socialnyx-setej.

10. Seryi A.V., Parshintseva A.S. K probleme formirovaniya zavisimosti ot sotsial'nykh setei u shkol'nikov podrostkovogo vozrasta // Problemy pedagogiki. 2016. № 9 (20). S. 12-15.

11. Skachkov M.A., Utemov V.V. Vliyanie sotsial'nykh setei na formirovanie lichnosti sovremennogo podrostka // Kontsept: nauchno-metod. zhurnal. 2013. № 8. S. 69-73.

12. Chelysheva I.V. Sotsial'nye seti v zhizni sovremennykh shkol'nikov // Mediaobrazovanie. 2014. № 2. S. 121-126.

13. Shakhmartova O.N., Nedoshivina I.V. Issledovanie motivov ispol'zovaniya sotsial'nykh setei mladshimi shkol'nikami // Izvestiya Penzenskogo gosudarstvennogo pedagogicheskogo universiteta im. V.G. Belinskogo. 2012. Vyp. № 28. S. 1348-1353.

14. Shubovich M.M., Yakutova Yu.A. Sotsial'naya aktivnost' starsheklassnikov v sfere sovremennykh informatsionnykh tekhnologii kak rezul'tat formirovaniya internet-kul'tury // Vestnik Orlovskogo gosudarstvennogo universiteta. Seriya «Novye gumanitarnye issledovaniya». 2012. № 7. S. 238-241.

15. Yur'eva E.A. Vliyanie sotsial'nykh setei na sotsializatsiyu i sistemu tsennostnykh orientatsii starshikh shkol'nikov // Vestnik Krasnoyarskogo gosudarstvennogo pedagogicheskogo universiteta im. V.P. Astaf'eva. 2012. № 4 (22). S. 218-221. 